\title{
One hundred years ago
}

\section{The psychology of 'auto-accusation'}

"AUTO-ACCUSATION" is a curious phenomenon which possesses both medical and legal interest. The committal of a notorious crime which excites popular imagination and which remains undetected for a time often leads to the appearance in law courts of self-accusing culprits who charge themselves with being the authors of the crime in question. Dr. Ernest Dupré of Paris in a paper read before the Annual Congress of French Alienists and Neurologists recently held at Grenoble attempts to delineate with exactitude the psychological nature of "auto-accusation" and to show that certain morbid elements play an important part in it. He points out that "auto-accusation" is not often or merely the result of a weakmindedness; the subject of it is a person who has positively developed general ideas of unworthiness, guilt, and remorse, and in a word is suffering from mild melancholia with vague delusions of guilt and sin. Another type of self-accuser is the proud and vain "degenerate" who with a brain warped by congenital anomaly of development constructs romances of which he readily persuades himself to be the hero or the martyr. There is, adds Dr. Dupré, a marked contrast between these two types. The one is abject, lowly, self-humiliating; the other proud, egoistic, and vain. Among other types of the same abnormality are found persons of alcoholic or hysterical character. The alcoholic self-accuser is one whose delusion generally has its starting point in nocturnal or morning hallucinations occurring in a state between sleeping and waking. The physical and mental characters associated with alcoholism permit such cases to be readily recognised and they are almost invariably observed in adult males. The female self-accuser is rarely seen in the law court and she is usually the subject of a marked hysteria. More often such a dement appears as an accuser of others and weaves extraordinary and plausible romances to bear out her statements. These generally refer to sexual assaults and personal violence sustained at the hands of others, but in rare instances she charges herself alone with such crimes as poisoning, abortion and adultery. Dr. Dupré finally points out that many unfortunate men and women who were mentally afflicted in one or other of the ways above mentioned and who accused themselves of poisoning, murder, communion with evil spirits, and the like, were in the Middle Ages gravely tried by legal or ecclesiastical tribunals and even suffered the death penalty or were burnt at the stake as witches and sorcerers, while in a more enlightened age they are now consigned to care in lunatic asylums or other suitable institutions.

\section{REFERENCE}

Lancet, 8 November 1902, p. 1270.

Researched by Henry Rollin, Emeritus Consultant Psychiatrist, Horton Hospital, Epsom, Surrey 